\title{
Are oil spills enhancing outbreaks of red tides in the Chinese coastal waters from 1973 to 2017?
}

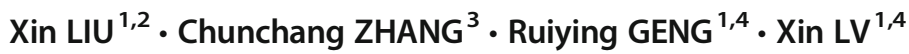 \\ Received: 13 January 2021 / Accepted: 19 May 2021 \\ (C) The Author(s), under exclusive licence to Springer-Verlag GmbH Germany, part of Springer Nature 2021
}

\begin{abstract}
Between 1973 and 2017, evidences of red tide outbreaks and oil spill accidents in the Chinese coastal waters were collected. Statistical analysis and multiple regression models were used to determine the relationship between the red tide and the oil spill. Major findings reveal that (1) the frequency of red tides positively correlates to the number of oil spills and the volume of oil spilled as well; (2) the higher percentage of small spills ( $<7$ tonnes) are more likely to enhance the outbreaks of red tides; (3) both EI Niño and storm events do not show any relationship with red tides; and (4) more severe oil spill with penalty recorded implies a higher possibility to trigger the red tide afterwards. Therefore, oil spill contingency management focusing on small oil spills and mitigating their spill effect by physical measures could be of benefit to decrease the frequency of red tides significantly. For example, it is suggested to carry out physical combat instead of chemical dispersants to remove the spilled small oil in the shallow coastal areas for reducing the outbreak risk of red tides after the oil spill.
\end{abstract}

Keywords Red tide $\cdot$ Oil spill $\cdot$ Correlation $\cdot$ Time series $\cdot$ Regression model $\cdot$ Shuffled surrogates

\section{Introduction}

Red tide is considered as the harmful algal bloom discoloring seawater in a short term (Huang et al. 2018). Red tide could be primarily made of toxic and non-toxic organisms (Liu et al. 2013) so that its outbreak is widely taken as one of the most serious marine disasters having a bad influence on coastal habitats and marine ecosystems (Park and Lee 2014). Some direct and adverse effects from the red tide include killing marine animals and excessively consuming oxygen of marine

Responsible Editor: Vitor Vasconcelos

Xin LIU

xliu@yic.ac.cn

1 Key Laboratory of Coastal Environmental Processes and Ecological Remediation, Yantai Institute of Coastal Zone Research, Chinese Academy of Sciences, Yantai 264003, People's Republic of China

2 Centre for Ocean Mega-Research of Science, Chinese Academy of Sciences, Yantai 264003, People's Republic of China

3 Shanghai Maritime University, Shanghai 201306, People's Republic of China

4 University of Chinese Academy of Sciences, Beijing 100049, People's Republic of China habitats, which further cause huge economic losses and affect human health. There exist a number of statistical works demonstrating that there is a significant increase in trend for red tides in the Chinese coastal waters for the past decades (Zhao et al. 2003). So far many studies focus on mechanism of the red tide and have pointed out that a variety of biological, hydrological, meteorological, and chemical indicators and their interactions may cause the red tide outbreaks (Wang et al. 2016). For example, a variety of models including decision tree (Park et al. 2011), multivariate linear regression (Pauline and Howard 1997), neural network (Velo-Suárez and Gutiérrez-Estrada 2007), stochastic dynamics (Huang et al. 2008), genetic programming (Sivapragasam et al. 2010), and time series (Qin et al. 2017) were proposed to predict the red tide occurrence. Due to the complexity of the marine system, it still remains difficult to predict the red tide by using those modeling techniques, as stated by Huang et al. (2018). Furthermore, those modeling results are not intuitive to shed light on coastal management for effective control of the red tide outbreaks in an operational way. Controlling any single indicator mentioned above in the coastal region is not only impossible but risky to meet a worse consequence.

In recent decades and throughout the China, the increasing outbreak of red tide suggests its likely link to coastal pollution (Luo and Jiao 2016). It was observed that red tide events 
increase as coastal pollution worsens (Suzuki 2016). However, oil spill as one of the major coastal pollutions has not yet been studied for its association with the red tide for a long term at a nation level, although only very few documents reported the algae bloomed following the Penglai 19-3 oil spill in the Chinese Bohai Sea as stated by Guo et al. (2012). Tang et al. (2019) investigated 21 oil spills in the world and found out of 21 spill cases, 14 algal blooms were observed by utilizing the remote sensing data and the time interval between algal blooms and oil spills varied between 3 and 10 months.

With the availability of observation data over a long period of time from 1973 to 2017 at the national scale of China, we made a first attempt to examine the relationship between the red tide events and the oil spill to fill the gap in the literature on the one hand and to provide operational methods for declining the outbreaks of red tide on the other hand. For a full comparison, we then extended such an analysis to natural events such as storms and EI Niño. However, other environmental factors such as temperature and nutrients that may influence the occurrence of HABs (harmful algal blooms) as well were not discussed in this paper. To characterize the response of red tide outbreaks to the oil spill, multiple regression models were proposed.

\section{Data and methods}

Red tide in the Chinese coastal waters has been monitored and reported by the State of Ocean Administration (SOA), China, since 1972. Annual red tide data were collected in each of local marine environmental monitoring centers distributed along the Chinese coasts. This study used the SOA red tide time series data for 45 years from 1973 to 2017.

Historical oil spills in the coastal waters originated from the Maritime Safety Administration (MSA), China. Such data records spill date, spill size, spill location, spill type, penalty applied, and spill reason for each accident at the national level of China from 1973 to 2017. Regarding penalty, only greater than CNY 10,000 were recorded. Spill size data varies as time goes. For example, data from 1973 to 2001 only focuses on spills over 50 tonnes; data from 2002 to 2013 has a focus on spills over 10 tonnes and data from 2014 to 2017 provides information on any spill size larger than 1 tonne. The oil spill data for each year from 1973 to 2017 used in this study includes the actual number of accidental oil spills, percentage of different spill size categories, the sum of volume spilled, and if fine/penalty was applied following the spill. According to the International Tanker Owners Pollution Federation (ITOPF), spills are generally categorized by size: $<7$ tonnes (small spill), 7-700 tonnes (medium spill), and $>700$ tonnes (large spill). Totally, there were 161 oil spills recorded for the period between 1973 and 2017 (see Table S1 for more details), the vast majority of which fall into the medium spill category. Such a bias could be explained by the fact that any spill size smaller than 50 tonnes was not available in the historical data from 1973 to 2001.

Storms hitting China were obtained from the Unisys Weather and then were analyzed in time series for this study (http://weather.unisys.com/hurricane). Years for the strong EI Niño events were collected from the Golden Gate Weather Services (http://www.ggweather.com/enso/oni.htm) and were coded into binominal data in the analysis: 1 for strong EI Niño and 0 for weak EI Niño.

\section{Statistical analysis}

The statistical analyses were performed with the EVIEWS version 10.0 statistical software (EVIEWS, QMS Inc., USA). The correlation between the red tide and the other environmental factors including storms, oil spills, and strong EI Niño was performed by using the Pearson's correlation. The strength of the relationship between paired data was interpreted through the Pearson's correlation index (CI) analysis, where the closer $\mathrm{CI}$ is to \pm 1 , the stronger their relationship is.

\section{Shuffled surrogates}

The time series data for red tides, oil spills, storms, and EI Niño are from non-linear systems. Additionally, the size of sample is limited to 45 . To further confirm the relationship between these paired data calculated by the Pearson's correlation index, we performed a null hypothesis test. For example, our null hypothesis is that, the occurrence of red tide is not associated with the oil spill (i.e., the red tide has no relationship with the oil spill). We tested this hypothesis by (i) generating surrogate data by randomly shuffling of the original time series of oil spill data; (ii) using Matlab programming for producing 1000 surrogate time series data of the original oil spills; (iii) batch run of 1000 times for calculating the Pearson's correlation coefficient between each of the surrogate data set of oil spill and the original red tide data (iv) deriving the mean value of the 1000's correlation coefficients; (v) computing the Z-score of the difference between such a mean value and the former Pearson's correlation coefficient produced by the paired original data sets between the red tide and the oil spill; and (vi) testing whether the $\mathrm{Z}$ score of their such a difference was significantly different from 0 (i.e., the null hypothesis can be rejected if the difference was significantly different from 0 ).

\section{Regression models}

Once the red tide is confirmed to be associated with the oil spill in the previous analysis, we move to evaluate their relationship in details. Here four regression models were proposed 
as seen below. Multiple regression analyses were conducted by EVIEWS 10 .

Model 1:

red_tide $=\alpha+\beta_{1} * N_{\text {spill }}+\mu_{i}$

Model 2:

$$
\begin{aligned}
\text { red_tide }= & \alpha+\beta_{1} * N_{\text {spill }}+\beta_{2} * P_{700}+\beta_{3} * P_{70-700} \\
& +\beta_{4} * P_{7-70}+\beta_{5} * P_{7}+\mu_{i}
\end{aligned}
$$

Model 3:

$$
\begin{aligned}
\text { red_tide }= & \alpha+\beta_{1} * N_{\text {spill }}+\beta_{2} * P_{700}+\beta_{3} * P_{70-700} \\
& +\beta_{4} * P_{7-70}+\beta_{5} * P_{7}+\beta_{6} * \text { Volume }_{\text {year }}+\mu_{i}
\end{aligned}
$$

Model 4:

$$
\begin{aligned}
\text { red_tide }= & \alpha+\beta_{1} * N_{\text {spill }}+\beta_{2} * P_{700}+\beta_{3} * P_{70-700} \\
& +\beta_{4} * P_{7-70}+\beta_{5} * P_{7}+\beta_{6} * \text { Volume }_{\text {year }} \\
& +\beta_{7} * \text { Penalty }_{\text {spill }}+\mu_{i}
\end{aligned}
$$

in which red tide and $\mathrm{N}_{\text {spill }}$ indicate the number of red tides and oil spills that occurred in the individual year, respectively; $\alpha$ is constant; $\mathrm{P}_{700}, \mathrm{P}_{70-700}, \mathrm{P}_{7-70}$, and $\mathrm{P}_{7}$ represent the percentage of different spill categories including large spills ( $>700$ tonnes), medium spills (70-700 tonnes), medium spills (7-70 tonnes), and small spills $(<7$ tonnes) for each year from 1973 to 2017 . Volume year $_{\text {is }}$ the annual volume spilled in total and Penalty year refers to whether a penalty fare was applied following any spill in that individual year. This variable takes 1 if the fine was applied to any spill in that year, otherwise $0 . \mu_{i}$ is a random and $\beta_{1-7}$ are parameters to be estimated.

\section{Results}

\section{Relationship between red tides and environmental factors}

There were totally 1570 red tides occurring in the Chinese coastal waters over 45 years during the period between 1973 and 2017 with an approximate average frequency of 35 times/year. The outbreaks of red tide have firstly gently increased from 1973 to 1992 as shown in Fig. 1. Then, it kept relatively stable with a mean of 16.5 times/year over 8 years between 1993 and 2000. In 2002 the frequency of red tides increased sharply and peaked to 119 in 2003. Despite a declining frequency of red tides after 2003, the risk of red tides remains still high up to an average of 68.5 times/year between 2004 and 2017.
We assessed frequencies of red tides along with the hits of storms, oil spills, and the occurrence of EI Niño events, respectively. It is noted that there is a strong trend between the red tide and the oil spill. The frequency of red tides is highly related to oil spills. The number of red tides per year is enhanced significantly as the annual frequency of oil spills increases. Their Pearson's correlation index is high up to + 0.618 with a significant level at $99 \%$ for a two-tailed test. However, no clear trend is observed for EI Niño events linked to red tides, as the correlation index between EI Niño events and red tides is very low to be -0.003 only. For example, during the very strong Niño events in 1997-1998, blooming of red tides were less frequent in the seas around China. Additionally, the correlation index between the storm events and red tides is low to be -0.09 , which demonstrated that there is no relationship between them as well. Similarly, storms hit China 13 times in 1974, while none of red tides was observed at that year.

\section{Red tide is highly associated with oil spills}

Due to the small sample of the data series observed, the statistical significance of the correlation between the red tide and the oil spill needs to be examined further. To validate such a relationship, we hence conducted a null hypothesis test, in which we assumed that the red-tide has no relationship with the oil spill. We simulated 1000 surrogate data sets based on shuffling the values of the original oil spill data set using Matlab programming. The mean value of correlation index between the red tide and the surrogate oil spill data is only 0.1225 and the Z-score value for comparing the Pearson's correlation indices calculated by using the original oil spill data and the surrogate oil spill data is high to 5.4693 (see Table 1 , generally speaking Z-score $>2$ is quite significant). Therefore, we rejected the null hypothesis firmly with a high level of confidence. That is to say, the occurrence of red tide is significantly associated with the oil spill in the Chinese coastal waters for the past 45 years from 1973 to 2017.

\section{Regression results}

Our regression results suggest that oil spills do affect the number of red tides (see Table 2 for the full regression results). The coefficient on the number of oil spills was positive and statistically significant $(\mathrm{P}<0.01)$ when this variable was only repressor. It remains significant and changes little in magnitude as controls are progressively added for percentage of spill categories, the sum of spill amounts, and the spill fine applied as shown in Model 2 to Model 4. Model 2 explains how the percentage of spill categories affects the occurrence of red tides in a relative way. Compared with other spill sizes from large oil spills ( $>700$ tonnes) to medium spills (7-700 tonnes), small oil spills ( $<7$ tonnes) play much more significant role to 


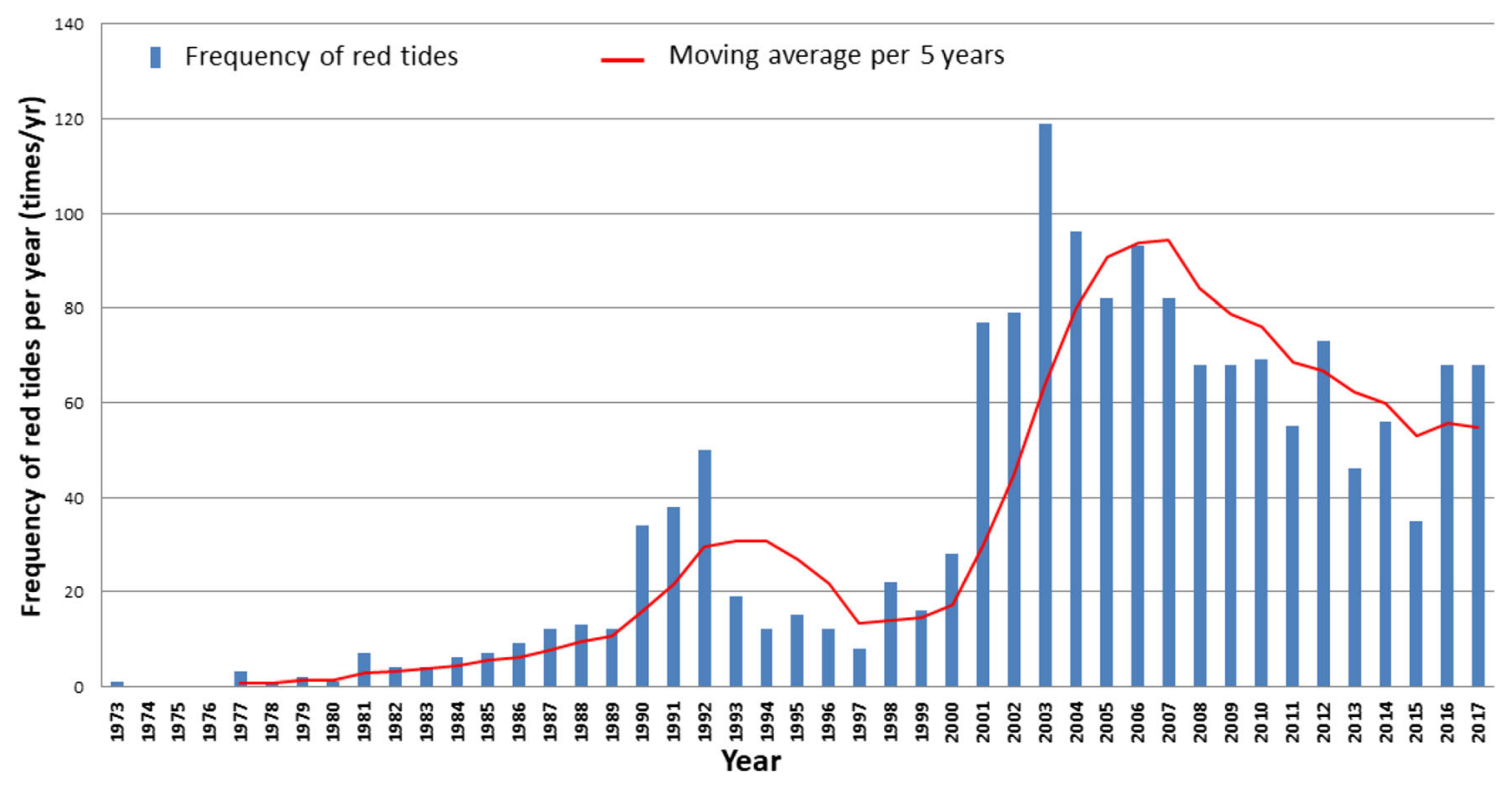

Fig. 1 Annual frequency of red tides in the Chinese coastal waters for a time period between 1973 and 2017. A moving average of red tides per 5 years is shown in red solid line

enhance the outbreaks of red tides. Many small oil spills instead of a single very large spill are likely to trigger the blooming of red tide. That is to say, more small spills happened, more red tides are possible to occur. One possible reason is that small spills result to low concentration of oil in waters, which further promote the growth of marine harmful algae, while high concentration of oil in the waters resulted from the large spill inhibits the algae to grow.

In Model 3, we added the total amount of oil spilled as a variable into the regression. Although the estimation on this variable is positive and statistically significant at $1 \%$ level, the coefficient of 0.0002 indicated that the number of red tides is not sensitive enough to the change of sum of spilled oil, which is explained partly by the fact that the independent variable is the number of red tides, not the spreading area (i.e., intensity) of red tides.

The spill fine applied is an important control because the severity of pollution may be responsible for triggering outbreak of the red tide. The spill fine was always applied if such an oil accident caused any sever damage to the surrounding coastal waters. As shown in Model 4, the coefficient is high up to 0.4916 on spill fine applied. An oil spill with fine applied indicated that such a spill caused severe damage to the marine environment, which has high likelihood to induce red tide subsequently. The Akaike information criterion (AIC) is the other index to evaluate the fitness of model and the model showing the smallest AIC is considered to be the most desirable (Akaike 1974). Although all AICs for four models are small enough ranging from 27.22 to 18.97 , Model 4 is most preferred. Such a judgment is consistent with the evaluation by using $\mathrm{R}^{2}$. Obviously, the fitness of $\mathrm{R}^{2}$ in Model 4 is $56.9 \%$, significantly higher than those of other models.

\section{Discussions}

To our knowledge, only very few documents reported the algae phenomena following the specific oil spill in the Chinese coastal waters. For example, the Penglai 19-3 oil spill happened in the Chinese Bohai Sea on 4 June 2011 with an

Table 1 Correlation between the number of oil spills and the frequency of red tide per year in the Chinese coastal waters by using original and surrogate oil spill data

\begin{tabular}{lll}
\hline & Original oil spill data & Surrogate oil spill data \\
\hline $\begin{array}{l}\text { Pearson's correlation index (between } \\
\text { red tide and oil spill) }\end{array}$ & $+0.618 * * *$ & $+0.1225(\mathrm{mean})$ \\
Sample size & 45 & 1000 simulations*45 \\
Significant level & $\mathrm{P}<0.001$; significant level $=99 \%$ & $5.4693 * * *$ \\
Z-score (comparing Pearson's correlation & $(* * *$ indicates significant level $=99 \%)$ & \\
$\quad$ indices generated by using original and surrogate data $)$ & & \\
\hline
\end{tabular}


Table 2 Estimates of model coefficients with the number of red tides per year as dependent variable using Poisson regression

\begin{tabular}{|c|c|c|}
\hline Model and variables & Coefficient estimate & $\begin{array}{l}\mathrm{R}^{2} \\
(\mathrm{AIC})\end{array}$ \\
\hline Model 1 (base model) & & \multirow{3}{*}{$\begin{array}{l}0.341 \\
(27.22)\end{array}$} \\
\hline Constant & $2.6708^{* * *}$ & \\
\hline The number of oil spills for each year & $0.2064^{* * *}$ & \\
\hline Model 2 (add spill categories to above) & & \multirow{7}{*}{$\begin{array}{l}0.494 \\
(20.39)\end{array}$} \\
\hline Constant & $1.8794^{* * * *}$ & \\
\hline The number of oil spills for each year & $0.1971^{\text {**** }}$ & \\
\hline The percentage of large oil spills(> 700 tonnes) & $-1.5565^{* * * *}$ & \\
\hline The percentage of medium oil spills (70-700 tonnes) & $0.8005^{\text {**** }}$ & \\
\hline The percentage of medium oil spills (7-70 tonnes) & $1.3522^{* * * *}$ & \\
\hline The percentage of small oil spills ( $<7$ tonnes) & $1.8611^{* * *}$ & \\
\hline Model 3 (add spill size to above) & & \multirow{8}{*}{$\begin{array}{l}0.535 \\
(19.86)\end{array}$} \\
\hline Constant & $1.8461^{* * * *}$ & \\
\hline The number of oil spills for each year & $0.1402^{* * * *}$ & \\
\hline The percentage of large oil spills(> 700 tonnes) & $-2.6381^{\text {***** }}$ & \\
\hline The percentage of medium oil spills (70-700 tonnes) & $0.7948^{* * *}$ & \\
\hline The percentage of medium oil spills (7-70 tonnes) & $1.5555^{* * *}$ & \\
\hline The percentage of small oil spills ( $<7$ tonnes) & $2.0679^{* * * *}$ & \\
\hline The total amount of oil spilled for each year (tonnes) & $0.0002^{* * * *}$ & \\
\hline Model 4 (add spill fine to above) & & \multirow{9}{*}{$\begin{array}{l}0.569 \\
(18.97)\end{array}$} \\
\hline Constant & $1.7388^{* * * *}$ & \\
\hline The number of oil spills for each year & $0.1307^{* * * *}$ & \\
\hline The percentage of large oil spills( $>700$ tonnes) & $-2.8494^{* * *}$ & \\
\hline The percentage of medium oil spills ( $70-700$ tonnes) & $0.5241^{* * *}$ & \\
\hline The percentage of medium oil spills ( $7-70$ tonnes) & $1.3973^{* * *}$ & \\
\hline The percentage of small oil spills ( $<7$ tonnes) & $1.6857^{* * *}$ & \\
\hline The total amount of spills for each year (tonnes) & $0.0002^{* * *}$ & \\
\hline The spill penalty applied (yes or no) & $0.4916^{* * *}$ & \\
\hline
\end{tabular}

Note: ${ }^{* * *}$ statistically significant at $1 \%$ level

${ }^{* * *}$ statistically significant at $5 \%$ level

* statistically significant at $10 \%$ level

AIC Akaike information criteria estimated economic loss of CNY 12.56 billion for the local fishery (Pan et al. 2015). Within 1 month after the spill, blooming of algae was observed at the shortest distance of $3.7 \mathrm{~km}$ from the spill site (Tang et al. 2019). Besides China, large plankton blooms were observed in other areas as well. For example, unusually large plankton blooms occurred in the contaminated waters of the Gulf of Mexico caused by the Ixtoc-I exploratory well oil spill (Jernelöv and Lindén 1981).

So far none of studies have investigated comprehensively the relationship between the red tide and the oil spill based on a long-term time series data at the national scale. Our work is the first attempt to associate the red tide to the oil spill in a quantitative way and further explains their relationship by a proposed regression model. Our findings, if confirmed by renewed studies in the future, will have a significant impact on coastal management to prevent the red tide outbreaks in not only the Chinese coastal waters, but similar coastal regions elsewhere.
The finding "oil spills causing significantly red tides and especially, small oil spills enhancing outbreaks of the red tide" was demonstrated merely based on our empirical analysis in this paper. In particular, the finding that small oil spills enhance outbreaks of the red tide is concerned. Generally, this can be explained by the fact that small spills may result to low concentrate of crude oil in waters. While, laboratory studies by Wang et al. (2009) supported that some specific species of marine algae exposed to low concentrate of oil tend to bloom. Ozhan and Bargu (2014) demonstrated toxin productivity for harmful algae such as Karenia brevis and Prorocentrum minimum increases at the lowest crude oil concentration $\left(0.66 \mathrm{mg} \mathrm{L}^{-1}\right)$, while higher crude oil concentrations led to significant growth inhibition and a decrease in toxin production. Zhang et al. (2002) found that lower doses of crude oil (i.e., $0.49 \mathrm{mg} / \mathrm{dm}^{3}$ ) promote the growth of the marine algae 
Skeleton Cosatum, which is a widely known species forming red tides in the Chinese Bohai Sea.

In reality, chemical dispersants were widely used in China to remove spilled oil, especially in case of small spills, due to the facts that small spills tend to form very thin oil film on sea surface and chemical dispersants work very well with the mix of thin oil and sea water. However, we did not examine the relationship of dispersants and the red tides in this paper due to the lack of dispersants data. A recent experiment by Almeda et al. $(2014,2018)$ showed oil spills and dispersants could cause the initiation of potential harmful algal blooms at the North Gulf of Mexico. Such a study is a solid evidence to support our finding that small spills with treatment of chemical dispersants undoubtedly enhance the risk of red tide blooming after the spill. It is suggested to use physical combat substituting chemical dispersants to respond to small oil spills in the shallow coastal waters of China. More evidence, especially studies on bio-physical models, chemical experiments, and field tests, are needed to confirm or challenge this paradigm. Renewed studies on the mechanism by which organisms of the red tide respond to chemical substance of oil spilled are important to support and refine this finding in the future.

There are uncertainties and limitations in our regression estimates. Firstly, $\mathrm{R}^{2}$ is only 0.569 for the regression Model 4, which means only $56.9 \%$ of the annual number of red tides can be explained by the proposed Model 4. Secondly, there might be a time interval between the oil spill accident and the occurrence of red tide. Due to the lack of data, we could not determine the role of this variable in the regression model. Thirdly, coefficient on the annual volume of spilled oil is significant, but very small to be 0.0002 . This could be attributed to the fact that we take the frequency of red tide substituting the spreading area of red tide as the dependent variable in the regression model. Other factors like temperature and location of spill (i.e., open sea or coastal areas) could have considerable influence on the bloom of red tide as well. We expect to collect these kinds of data to improve the modeling in the future.

\section{Conclusion}

Our study initially found the positive correlation between the red tide occurrence and the number of oil spill pollution based on a long-term historic data from 1973 to 2017 at the national scale of China. Our major findings concluded that, compared with the large oil spill, the higher percentage of small spills $(<$ 7 tonnes) are more likely to enhance the blooming of red tide. Both EI Niño and storm events have no relationship with red tides based on the statistical checks. Oil spill contingency management focusing on small oil spills and mitigating their spill effects could be of benefit to decline the frequency of red tide significantly. The findings from this study shed light on the preventative management of red tide outbreaks in the Chinese coastal waters and similar coastal region elsewhere.

Supplementary Information The online version contains supplementary material available at https://doi.org/10.1007/s11356-021-14549-3.

Acknowledgments We thank colleagues Jie GUO for firstly reading the manuscript and providing comments for improvements. We also thank the editors and reviewers for their helpful comments.

Authors' contributions X. LIU initiated the research and C. ZHANG provided the oil spill data. X. LIU, R. GENG, and X. LV analyzed the data. X. LIU wrote the paper.

Funding This study was financially supported by the Key Deployment Project of the Centre for Ocean Mega-Research of Science, Chinese Academy of Sciences (No: COMS2019J05) and the Key Program of National Natural Science Foundation of China (No. 41530966).

Data availability All data generated or analyzed during this study are included in the section of the supplementary information in this article.

\section{Declarations}

Ethics approval Not applicable.

Consent to participate Not applicable.

Consent to publish Not applicable.

Competing interests The authors declare that they have no competing interests.

\section{References}

Akaike H (1974) A new look at the statistical model identification. IEEE Trans Autom Control 19:716-723

Almeda R, Hyatt C, Buskey EJ (2014) Toxicity of dispersant Corexit9500A and crude oil to marine microzooplankton. Ecotoxicol Environ Saf 106:76-85

Almeda R, Cosgrove S, Buskey EJ (2018) Oil spills and dispersants can cause the initiation of potentially harmful dinoflagellate blooms ("Red Tides"). Environ Sci Technol 52:5718-5724

Guo J, Liu X, Xie Q (2012) Characteristics of the Bohai Sea oil spill and its impact on the Bohai Sea ecosystem. Chin Sci Bull 58:2276-2281

Huang D, Wang H, Feng J, Zhu Z (2008) Modelling algal densities in harmful algal blooms (HAB) with stochastic dynamics. Appl Math Model 32:1318-1326

Huang J, Liu H, Yin K (2018) Effects of meteorological factors on the temporal distribution of red tides in Tolo Harbour, Hong Kong. Mar Pollut Bull 126:419-427

Jernelöv A, Lindén O (1981) Ixtoc I: A Case Study of the World's Largest Oil Spill. Ambio 10:299-306

Liu LS, Zhou J, Zheng BH, Cai WQ, Lin KX, Tang JL (2013) Temporal and spatial distribution of red tide outbreaks in the Yangtze River Estuary and adjacent waters, China. Mar Pollut Bull 72:213-221

Luo X, Jiao J (2016) Submarine groundwater discharge and nutrient loadings in Tolo Harbor, Hong Kong using multiple geotracer- 
based models, and their implications of red tide outbreaks. Water Res 102:11-31

Ozhan K, Bargu S (2014) Responses of sympatric Karenia brevis, Prorocentrum minimum and Heterosigma akashiwo to the exposure of crude oil. Ecotoxicology 23:1387-1398

Pan G, Qiu S, Liu X, Hu X (2015) Estimating the economic damages from the Penglai 19-3 oil spill to the Yantai fisheries in the Bohai Sea of northeast China. Mar Policy 62:18-24

Park S, Lee SR (2014) Red tides prediction system using fuzzy reasoning and the ensemble method. Appl Intell 40:244-255

Park S, Lee SR, Park JH, Park Y, Jung MA, Pyo SJ, Kim KS (2011) Prediction of red tide blooms using decision tree model. IEEE Int Conf Convergence:710-713

Pauline EK, Howard A (1997) Statistical analysis of algal and water quality data. Hydrobiologia 349:59-63

Qin M, Li Z, Du Z (2017) Red tide time series forecasting by combining ARIMA and deep belief network. Knowl-Based Syst 125:39-52

Sivapragasam C, Muttil N, Muthukumar S, Arun VM (2010) Prediction of algal blooms using genetic programming. Mar Pollut Bull 60: $1849-1855$

Suzuki C (2016) Assessing change of environmental dynamics by legislation in Japan, using red tide occurrence in Ise Bay as an indicator. Mar Pollut Bull 102:283-288
Tang DL, Sun J, Zhou L, Wang SF, Singh RP, Pan G (2019) Ecological response of phytoplankton to the oil spills in the oceans. Geomatics Nat Hazards Risk 10:853-872

Velo-Suárez L, Gutiérrez-Estrada JC (2007) Artificial neural network approaches to one-step weekly prediction of Dinophysis acuminata blooms in Huelva (West- ern Andalucía, Spain). Harmful Algae 6: 361-371

Wang CY, He SJ, Li YT, Hou XY, Yang CY (2009) Study on the state and ecological effect of spilled oil pollution in Chinese Coastal Waters. Mar Sci 33:57-60

Wang C, Wang Z, Wang P, Zhang S (2016) Multiple effects of environmental factors on algal growth and nutrient thresholds for harmful algal blooms: application of response surface methodology. Environ Model Assess 21:247-259

Zhang L, Wang XL, Han XR, Zhu CJ, Shi XY, Jiang FH, Yang NJ (2002) Effects of petroleum hydrocarbon on the growth of marine algae: experiment versus model. J Ocean Univ Qingdao 32:804-810

Zhao L, Zhao DZ, Zhang XY, Zhang FS (2003) Spatial and temporal distribution of harmful algae blooms and hazard grading in China. Mar Environ Sci 22:15-19

Publisher's note Springer Nature remains neutral with regard to jurisdictional claims in published maps and institutional affiliations. 